\title{
IDENTIDAD CULTURAL EN LOS PROCESOS DE INTEGRACIÓN REGIONAL
}

\section{IDENTIDADE CULTURAL NOS PROCESSOS DE INTEGRAÇÃO REGIONAL}

Christian G. Sommer ${ }^{\star}$

Resumen: Desde fines del siglo XX, los países sudamericanos han procurado estrechar sus vínculos a través de la conformación de procesos de integración como la Comunidad Andina, el MERCOSUR y más recientemente con la CELAC. Pero para que los objetivos de integración de los países y de los pueblos alcancen un mayor fortalecimiento, es trascendental el fortalecer los vínculos culturales comunes de los pueblos sudamericanos, a fin de afianzar una verdadera identidad cultural regional.

Resumo: Desde o final do século XX, os países sul-americanos têm procurado fortalecer seus laços por meio do estabelecimento de processos de integração como a Comunidade Andina, o Mercosul e, mais recentemente, a CELAC. Mas, para que os objetivos de integração dos países e dos povos alcancem maior vigor, transcedental se faz fortalecer os laços culturais comuns dos povos da América do Sul, a fim de garantir uma verdadeira identidade cultural regional.

Palabras clave: Integración Regional, Identidad, Cultura, Regímenes internacionales

Palavras-chave: Integração Regional, Identidade, Cultura, Regimes internacionais

\section{INTRODUCCIÓN}

Los procesos de integración regional han sido ampliamente estudiados como uno de los fenómenos que emergieron con fuerza en

\footnotetext{
* Facultad de Derecho - Universidad Nacional de Córdoba (Argentina). Doctor en Derecho (Universidad Nacional de Córdoba). Abogado (UNC). Profesor titular de Derecho Internacional Público en la Universidad Católica de Córdoba. Profesor de Derecho Internacional y de Derecho de la Integración en la Facultad de Derecho Universidad Nacional de Córdoba. Miembro de la Asociación Argentina de Derecho Internacional (AADI).
} 
el marco del proceso de la globalización.

Uno de los factores que merecen atención y que pueden servir de parámetro para medir el estado de evolución dichos esquemas integrados, es la construcción de espacios de interrelación multi e intercultural que han favorecido o estancado dichos procesos.

Los espacios culturales se han visto en los últimos años, influenciados ante los nuevos procesos de integración regional y subregional existentes. Ello ha incidido tanto las relaciones estatales como las dinámicas internas de los países con una mayor interacción de las manifestaciones culturales.

Es por ello que interesa hacer una reflexión vinculando la construcción del colectivo regional, como una identidad mayor a la identidad nacional y los regímenes de integración regional, posibilitando en el caso de los tres sistemas de integración sudamericanos más relevantes: MERCOSUR (Mercado Común del Sur), CAN (Comunidad Andina) y CELAC (Comunidad de Estados Latinoamericanos y Caribeños) señalar sus dinámicas y objetivos implementados.

\section{REGÍMENES DE INTEGRACIÓN REGIONAL}

Los regímenes de integración requieren, para evitar la retracción de los actores regionales, de mecanismos que permitan superar los estadios de incertidumbre y profundización de divergencia de intereses y en tal sentido, permitan un desarrollo de la vida en común y la satisfacción de los intereses de la identidad colectiva regional.

Siguiendo a Keohane, para que exista el institucionalismo en el escenario internacional es necesario que se den dos condiciones:

a) que los actores tengan intereses mutuos por lo tanto, que esperen beneficios potenciales de la cooperación y

b) que las variaciones en el grado de institucionalización ejerzan efectos sustanciales en el comportamiento del actor, esto es como consecuencia de la dinámica del sistema internacional que lleva implícito la variación en el comportamiento de los actores ${ }^{1}$.

En tal sentido, los Estados tienen intereses mutuos y los regímenes o acuerdos institucionales, son una variable en la dinámica de la política internacional. Ellos surgen cuando los actores abandonan la toma de decisiones independientes para alcanzar sus intereses de cooperación y optan por "(...) enfrentar el dilema entre los intereses y las aversiones comunes en forma conjunta a partir de las expectativas y modelos de conductas y prácticas, en los que la acción conjunta es lo relevante".

1 KEOHANE Robert (1993) Instituciones Internacionales y Poder Estatal. Ensayo sobre Teoría de las Relaciones Internacionales. Buenos Aires: GEL.

2 MURILLOZAMORA Carlos (2004) “Aproximación a los Regímenes de Integración Regional”. Revista Electrónica de Estudios Internacionales. (8), [online]. Disponible en: http://www.reei. org/index.php/revista/num8/articulos/aproximacion-regimenes-integracion-regional. Fecha 
Esta búsqueda de cooperación para alcanzar los intereses a través de acciones conjuntas, vincula a los regímenes internacionales con los procesos de integración en tanto éstos se conciben como procesos mediante el cual dos o más gobiernos adoptan, con el apoyo de instituciones comunes, medidas conjuntas para intensificar su interdependencia y obtener así beneficios mutuos.

Por lo tanto el régimen se incorpora al proceso de construcción regional como parte de la construcción del nuevo "sujeto" (en términos internacionales) que expresa una nueva identidad y nuevos intereses a alcanzar en una dimensión espacial de mayor envergadura. Vista de la manera descripta la aparición de la integración regional supone la transferencia de potestades y responsabilidades de actores nacionales a otro de identidad regional sin que ello implique la desaparición de las individualidades nacionales.

En la construcción de esta nueva identidad regional, influyen factores endógenos y exógenos, lo que impide medirlos en términos de avance lineal sino apreciarlos en términos de un proceso de construcción dinámico con avances y retrocesos donde la fortaleza y consolidación de los regímenes estructurantes podrán dar robustez a la integración permitiendo el enriquecimiento y efectividad de una identidad colectiva mayor en beneficio de las identidades individuales.

Para Murillo Zamora, este proceso de construcción puede determinarse a través de ciertos elementos:

a) inicio y expansión de los canales institucionales centrales para los flujos de transacción política;

b) expansión de las redes institucionales;

c) expansión cuantitativa y cualitativa de transacciones transnacionales entre grupos políticos no gubernamentales y crecientes contactos entre estos grupos y las instituciones regionales ${ }^{3}$.

A su vez, el esquema regional que resulta de los esfuerzos de los actores nacionales está fundamentado en los principios, normas $\mathrm{y}$ reglas que condicionan las acciones de los actores que conforman el colectivo. A través del aprendizaje y la socialización van generando nuevos principios, normas y reglas que dan lugar a un mayor grado de legalización y, por consiguiente, a una más sólida institucionalidad. Como se sostiene:

(...) cabe señalar que en la construcción de la conciencia y la cohesión regional inciden múltiples aspectos. Incluso, por ejemplo, es posible mencionar que los mitos juegan un rol importante en la construcción

de consulta [10/01/2013].

3 MURILLO ZAMORA Carlos (2004) "Aproximación a los Regímenes de Integración Regional”. Revista Electrónica de Estudios Internacionales. (8), [online]. Disponible en: http:// www.reei.org/index.php/revista/num8/articulos/aproximacion-regimenes-integracionregional. Fecha de consulta [10/01/2013]. 
de un esquema regional y una comunidad imaginada. Por eso la construcción de nuevos agentes es facilitada por el conocimiento compartido, lo que alcanza un mayor nivel en una región, sobre todo en un área temática específica en donde, además, convergen los intereses de los agentes ${ }^{4}$.

Ente estos nuevos agentes, en un espacio sociocultural, las ciudades son el territorio privilegiado de la conjunción de prácticas, valores y conflictos a partir de los cuales se define la calidad integral de vida de las personas y los grupos; la cual excede la mera concepción de la dimensión económica. Cabe destacar el trabajo que viene desarrollándose en la búsqueda de actividades culturales que promueven la integración de los pueblos, la Unidad Técnica de la reunión de Mercociudades ${ }^{5}$, en el contexto del sistema de integración MERCOSUR. Desde su puesta en marcha en el año 1995, esta Unidad Temática viene promoviendo el debate en torno al desarrollo cultural de las ciudades y las posibilidades de los gobiernos locales de promover políticas culturales inclusivas, respetuosas de la diversidad cultural de los pueblos. En ese contexto, la UTC participó del II Encuentro de Ciudades y Universidades realizado en Montevideo, del Encuentro Iberoamericano de Cultura que tuvo lugar en Quilmes y realizó reuniones en ciudades como Valparaíso (Chile), Belo Horizonte (Brasil), Buenos Aires y San Fernando del Valle de Catamarca (Argentina), Valencia y Barquisimeto (Venezuela) y San José de Mayo y Trinidad (Uruguay), entre otros. Para 2014 se propone generar un espacio de discusión sobre "Comunicación y Cultura" y participar activamente del debate abierto a 10 años de la puesta en vigencia de la Agenda 21 de la Cultura.

Pero además, los espacios culturales que se generan desde las ciudades cuentan en su impronta con una interacción cultural que es cotidiana en un ámbito particular, como son los centros urbanos situados en áreas fronterizas. Como sostienen los expertos, en estas áreas, las experiencias socioeconómicas y culturales son y han sido compartidas desde siempre, generando una matriz regional de estructuras sociales, económicas y culturales superpuestas. En este sentido, las fronteras requieren una atención especial. Simultanéateme marcan lo que une y lo que separa. Aunque a menudo las fronteras geográficas entre países han sido restringidas por diferencias entre los países, el flujo y la interacción entre gente de diferentes nacionalidades nunca se detuvo. En la interacción cotidiana, ese flujo de hombres y mujeres entre ciudades

4 MURILLO ZAMORA Carlos (2004) “Aproximación a los Regímenes de Integración Regional”. Revista Electrónica de Estudios Internacionales. (8), [online]. Disponible en: http:// www.reei.org/index.php/revista/num8/articulos/aproximacion-regimenes-integracionregional. Fecha de consulta [10/01/2013].

5 Ver: http://www.mercociudades.org/UTC 
fronterizas, conforman prácticas culturales comunes que se entrelazan ${ }^{6}$.

\section{CONSTRUCCIÓN DE IDENTIDADES COLECTIVAS}

El ámbito sudamericano registra una gran heterogeneidad a la vez que homogeneidad entre lo que puede enunciarse como culturas nacionales. Contrario sensu al caso europeo, los países sudamericanos han compartido una lengua común o próxima en el caso brasileño, una religión mayoritariamente común, una historia y costumbres similares. Sin embargo, los procesos históricos nacionales han sido desfavorables a la integración en la medida que han acogido y valorizado las contiendas entre países, pero primordialmente por el aislamiento y el desconocimiento mutuo durante la mayor parte del siglo XIX y gran parte del XX, dada la gravitación tradicional de sus relaciones con las antiguas metrópolis europeas y con el centro de poder de los Estados Unidos.

Pero a diferencia de otros procesos de integración como el europeo, los contrastes no se presentan en el nivel de homogeneidad cultural entre las naciones, sino en la base misma de la actual cultura latinoamericana. Mientras en Europa las diversidades nacionales se compensaron en los orígenes comunes de las culturas, la comunidad cultural latinoamericana se compensa con la diversidad de los orígenes culturales de cuatro vertientes principales: países ${ }^{7}$.

a) La vertiente original americana que subyace en todos nuestros

b) La vertiente europea, que es la que unifica lenguas y religión.

c) La vertiente proveniente de África. Infortunadamente ha sido la más ignorada y desarraigada.

d) La vertiente asiática (más reciente) cuya importancia está presente de manera principal en las naciones andinas ${ }^{8}$.

De esta confluencia de culturas, se ha generado un sincretismo que permite la búsqueda de patrones comunes de cultura regional cada vez más reconocida por los actores sociales en conjunto. Por ello, la responsabilidad de los gobiernos de promover un acceso equitativo a los diferentes mercados y un intercambio cultural a través de fomentar el conocimiento entre las distintas culturas en el marco de los procesos

6 JELIN Elizabeth (2001) "Los movimientos sociales y los actores culturales en el escenario regional. El caso del Mercosur”. En Gerónimo de Sierra (ed.) Los rostros del Mercosur. El difícil camino de lo comercial a lo societal. Buenos Aires: CLACSO.

7 Como sostiene Methol Ferré, puede hablarse de una civilización atlántica sudamericana integrada por las culturas y subculturas correspondientes a las distintas etnias y pueblos existentes, países vinculados desde los tiempos prehistóricos. (Methol Ferré, 1997).

8 SANZ MANRIQUE Fernando (1998) "La integración cultural en la integración Internacional”. En Centro de Formación para la Integración Regional (CEFIR). N ${ }^{\circ}$ 1998-9. [online]. Disponible en: <http://cefir.org.uy/documentacion/publicaciones-cefirv $>$ Fecha de consulta $[15 / 01 / 2013]$. 
de integración, debe ser central. Esta es una opción que, apareciendo como meramente política, resultaría indispensable para que las propias relaciones económico-comerciales no fracasen en un mundo en el que, más allá de la globalización, las culturas siguen teniendo y defendiendo sus particularidades ${ }^{9}$.

Si el proceso de integración regional es visto como la convergencia de intereses culturales de los agentes colectivos esto conduce, necesariamente a la creación de una identidad regional que, a su vez, produce en el escenario hemisférico y regional la emergencia de un nuevo agente colectivo, es decir un "ser cultural común". Ello porque la identidad está arraigada en la esencia subjetiva del agente/individuo y requiere de una relación externa para que el hecho interno sea reconocido como tal. Por lo tanto el agente no construye su identidad en el vacío. "Es decir, según las circunstancias el "yo" identifica intereses comunes con los de los Otros, llegando a pensar en términos de "nosotros", lo que genera una "identidad colectiva", en la cual todos procuran preservar y fortalecer su conocimiento compartido (cultura) ${ }^{10}$.

Esta construcción de una identidad colectiva tiende a una nueva forma de interacción social y, por lo tanto, no está exenta de dificultades y conflictos en los distintos niveles de intereses colectivos, que a la postre son agregados a la identidad individual. Por ello es trascendental que los Estados Partes en los regímenes de integración regional puedan enfocar sus esfuerzos en la búsqueda de esas identidades comunes y la mayor interacción de las expresiones culturales de sus pueblos, que posibiliten la construcción o acercamiento de ese ser cultural común.

Llevado el argumento anterior al plano de los procesos de integración regional de MERCOSUR y CAN, surge la necesidad de poner atención en la promoción de los espacios de expresión cultural que tiendan a una construcción de identidad regional común, pero sin que ello implique el solapamiento de las identidades individuales de los agentes intervinientes, esto es, a la identidad determinada por razones de nacionalidad.

En este marco los Estados, como agentes colectivos pueden asumir identidades regionales sin abandonar sus identidades nacionales para que los nuevos intereses derivados no resulten contradictorios porque, de ser así, es probable que el Estado que se sienta afectado se retraiga y se paralice el proceso de integración.

9 CALDERÓN Fernando y SZMUKLER Alicia (1999) "Aspectos culturales de las migraciones en el MERCOSUR". Proyecto MOST - Mercosur: espacios de interacción, espacios de integración-. UNESCO. Documentos de Debate, $n^{\circ} 31$. [online] Disponible en: $<$ http://unesdoc. unesco.org/images/0011/001149/114955so.pdf $>$. Fecha de consulta [10/01/2013]

10 MURILLO ZAMORA Carlos (2004) "Aproximación a los Regímenes de Integración Regional”. Revista Electrónica de Estudios Internacionales. (8), [online]. Disponible en: $<$ http://www.reei.org/index.php/revista/num8/articulos/aproximacion-regimenes-integracionregional $>$. Fecha de consulta $[10 / 01 / 2013]$. 
La multiculturalidad de nuestras sociedades es hoy un hecho reconocido y está arraigada a la historia y existencia de nuestra región. La diversidad cultural se convierte en un factor relevante, tanto para hacer que se reconozca su especificidad en las negociaciones comerciales internacionales, como para que se reconozca la identidad cultural o religiosa como persona y como comunidad. Esto implica entender la diversidad cultural como un soporte para el desarrollo de todas las culturas existentes en el espacio regional. Esto nos transporta de una lógica mono(cultural) a una lógica inter(cultural), lo que implica no sólo el reconocimiento de la diversidad, el diálogo y la interacción entre personas y comunidades, sino también el cuestionamiento en la reciprocidad y la dinámica de cambios, reales y potenciales ${ }^{11}$.

Por su parte, Alain Touraine describió esta perspectiva cuando afirmaba que no hay que hacer hincapié en la distancia entre las culturas, sino en la capacidad de los individuos de construir un proyecto de vida en común. El autor considera que habría que hablar menos de confluencia entre culturas, y más de historias de individuos que pasan de una situación a otra y que reciben de diversas sociedades y culturas los elementos que conformarán su personalidad ${ }^{12}$.

Sin embargo otros autores sostienen que más que hablar de "cultura" en singular, debe hablarse de culturas en plural. Como las identidades, las culturas serán por tanto plurales, en desarrollo permanente, en interacción constante. Y es que en la confrontación y el diálogo con el "otro" es que llegaremos a conocernos y a ser conscientes de nuestras identidades y nuestras culturas ${ }^{13}$. Claude Lévi-Strauss ya había hecho hincapié en ello: el descubrimiento de la alteridad tiene que ver con una relación, no con una barrera. La cultura se construye con relación al otro, en la confrontación de lo idéntico y la alteridad, del aquí y el allá, del presente y del pasado. Más que un lugar de comunicación entre el yo y el otro, los espacios de contacto son campos interactivos donde estas entidades toman conciencia de ellas mismas y producen su identidad $^{14}$.

\section{LOS MECANISMOS DE FORTALECIMIENTO CULTURAL. MERCOSUR, COMUNIDAD ANDINA Y CELAC}

Como se expresó anteriormente, la formación de mercados

11 REY Micheline (1997) "The rol of local and regional authorities in the development of programmes for migrants and minorities from and intercultural perspective". En Council of Europe. Migrants and Minorities in the community. Studies and Texts $\mathrm{n}^{\circ} 53$.

12 TOURAINE Alain (1995) ¿Qué es la Democracia? Montevideo: Fondo de Cultura Económica.

13 WEBER Raymond (2003) "Los nuevos desafíos de la cooperación cultural europea". Revista Pensar Iberoamérica. Revista de Cultura. (2).

14 LÉVI-STRAUSS Claude (1999) Raza y Cultura. Barcelona: Edit. Altaya. 
regionales constituye en primer lugar una respuesta desde los distintos países de la región para poder enfrentar los efectos que produce la globalización y en particular, permitir que en forma coordinada en sus políticas macroeconómicas puedan hacer frente a las relaciones con otros mercados regionales o economías competitivas. Una de las particularidades de los procesos de integración en América del Sur, son los problemas planteados en torno a la desigualdad o disparidad tanto económica como socio cultural entre los países que firman acuerdos de este tenor. Así, debería ser de interés para los Estados Partes de estos procesos, que los aspectos culturales permitan una efectiva integración entre los ciudadanos y grupos que conforman los procesos de integración aludidos. En el caso de MERCOSUR, entre sus Estados Partes no habría grandes divergencias culturales. Los países miembros del MERCOSUR poseen afinidades culturales fuertes, se trata en primer lugar de una alianza económico-comercial que sí puede lograr un mayor acercamiento cultural, pero que en principio sólo está pensada para fortalecer la integración económica. Esto no significa desconocer los esfuerzos orientados a lograr una mayor integración y aceptación cultural ${ }^{15}$.

Fruto de ese objetivo es que dentro de la institucionalización del MERCOSUR, existen diversas experiencias en funcionamiento. A fin de fortalecer los aspectos normativos de estas iniciativas, los Estados Partes suscribieron en diciembre de 1996, un Protocolo de Integración Cultural del MERCOSUR (Protocolo de Fortaleza), el que los Estados Partes se comprometieron a promover la cooperación y el intercambio entre sus respectivas instituciones y agentes culturales, con el objetivo de favorecer el enriquecimiento y la difusión de las expresiones culturales y artísticas del MERCOSUR, a la vez que promueven la investigación de temas históricos y culturales comunes, incluyendo aspectos contemporáneos de la vida cultural de sus pueblos, de modo que los resultados de las investigaciones puedan servir como aporte para la definición de iniciativas culturales conjuntas (art. II y V).

En líneas generales, el documento-base en materia cultural reconoce la diversidad de las identidades, favorece el intercambio cultural y contempla como prioridad la formación de recursos humanos. La elaboración de políticas culturales dentro de este marco conceptual queda en manos de Comisiones Técnicas, responsables, por un lado, de trabajar en la convergencia de legislaciones específicas sobre incentivos fiscales a la cultura, derechos de autor y propiedad intelectual; y de tratar de salvar, por otro, los desajustes que se dan entre "el concepto de cultura patrimonialista, que prevalece en las dependencias estatales de cultura, y un enfoque comercial destinado al tratamiento de los

15 RECONDO Gregorio (1997) MERCOSUR. La dimensión cultural de la integración. Buenos Aires: Ciccus. 
productos industriales"16.

Hasta la actualidad, se han creado diversas iniciativas. Una de ellas es la denominada MERCOSUR CULTURAL, que procura profundizar los lazos culturales y sociales para una mejor prospectiva de integración regional. Es por esta razón que la Cultura, como ámbito privilegiado y fundamental en la generación de lazos de integración, adquiere un rol destacado en este proceso. El mismo está estructurado en (a) Reuniones de Ministros de Cultural, integrado por las máximas autoridades de cultura de cada uno de los Estados; (b) Comité Coordinador General, lo conforman los más altos funcionarios del área de asuntos internacionales y/o cooperación del organismo de cultura de cada Estado y, (c) Comisiones Técnicas, donde tratan temas específicos que luego son incorporados a la agenda de Ministros. Uno de los primeros logros fue el establecer un sello MERCOSUR para los aspectos culturales. El sello MERCOSUR, facilita la fiscalización de circulación de los bienes culturales de proyectos que sean autorizados y es el elemento visual que identifica la voluntad de integración de todos los países miembros. Los procesos de integración cultural tienen como objetivo la promoción del conocimiento recíproco y el fortalecimiento de las manifestaciones artísticas, los valores, la idiosincrasia de los pueblos, atendiendo a la diversidad cultural de cada uno de ellos.

A su vez se cuenta con un Sistema de información Cultural (SICSUR), Aprobado por los ministros de cultura del MERCOSUR en diciembre de $2008^{17}$. El SICSUR es un ámbito específico para la generación de datos válidos sobre la economía cultural de la región y de cada uno de los Estados Partes y Asociados del MERCOSUR.

De acuerdo con la UNESCO, el Estado moderno debe garantizar tanto el derecho a la cultura como el derecho a la educación y al trabajo. En otras palabras, el acceso a la cultura no se da en forma lineal sin que estén dadas las condiciones materiales para la satisfacción del derecho social y económico de los ciudadanos. ¿Cuál es la respuesta de Estados comprometidos en procesos de integración para tratar de equilibrar las asimetrías culturales que la apertura económica exaspera? En el MERCOSUR, el fomento al patrocinio de terceros (fundaciones, empresas y autores) conviven con los esfuerzos y financiamientos que los Estados disponen a las iniciativas culturales. En lo que respecta a la participación del sector privado, tanto en la 2da. Reunión Especializada de Cultura (Asunción, 1995) como en el Protocolo de Integración Cultural (Fortaleza, 1996), se acordó estimular la creación de incentivos fiscales para el sector privado que favorezca la producción, coproducción

16 GARCÍA CANCLINI Néstor y MONETA Carlos (eds.) Las industrias culturales en la integración latinoamericana. Buenos Aires: Eudeba.

17 Ver: http://www.sicsur.org 
y ejecución de proyectos considerados de interés cultural ${ }^{18}$. Por su parte, las políticas públicas desarrolladas por los Estados partes en los procesos de integración regional (tanto MERCOSUR como CAN) reflejan un claro auge del financiamiento en proyectos de industrias culturales y la realización de actividades en conjunto como marco para el fortalecimiento de la búsqueda de una construcción cultural regional y colectiva. Muestra de ello son los constantes eventos que se propician a través de los Ministerios de Cultura de los Estados Partes, o de iniciativas mancomunadas, con expresiones como los festivales de Teatro del MERCOSUR, entre otras iniciativas.

En lo que respecta a la CAN, se puede apreciar en este espacio regional de integración, los mayores avances institucionales en procura de brindar a las cuestiones del desarrollo y promoción de la cultura regional, un rol de valía como proceso de consolidación de la identidad regional andina.

Las actividades de la Secretaría General de la CAN en este ámbito se sustentan en la Agenda Estratégica Andina, aprobada por el Consejo Andino de Ministros de Relaciones Exteriores en forma ampliada con la Comisión de la CAN, en febrero de 2010. La Agenda Estratégica contempla, en el área cultural, el desarrollo de programas y proyectos destinados a impulsar las Industrias Culturales y fomentar las nuevas expresiones de participación ciudadana para promover una cultura andina de la integración; entre otros. Dentro de la implementación del Plan Andino para el Desarrollo de las Industrias Culturales, pueden enunciarse programas como:

1. Foro Andino de Legislación Cultural.

2. Fondo Andino para el Fomento a la Co-producción, Circulación y Exhibición de bienes y servicios culturales.

3. Programa de Movilidad para Estudios Culturales.

4. Sistema Andino de Información Cultural. (CULTURANDE) ${ }^{19}$

5. Feria de Proyectos Culturales Andinos.

Mediante la Decisión 76020, el Consejo Andino de Ministros de Relaciones Exteriores (CAMRE) creó el Consejo Andino de Ministros de Cultura y Culturas y le asignó, como una de sus funciones, "formular propuestas de estrategias subregionales para el desarrollo y fomento de las industrias culturales en el marco de un Plan Andino de Industrias Culturales" y "crear el Comité Andino de Industrias Culturales".

En su primera reunión celebrada el 16 de marzo de 2012, el

18 MUDROVCIC María Eugenia (2001) "Políticas Culturales en los procesos de integración regional. El sector editorial en el MERCOSUR". Revista Iberoamericana, 47(197), [online] Disponible en: <http://revista-iberoamericana.pitt.edu/ojs/index.php/Iberoamericana/issue/ view/216> Fecha de consulta [20/01/2013].

19 http://www.culturande.org/

$2023^{\circ}$ Reunión Ordinaria del Consejo Andino de Ministros de Relaciones Exteriores. 22 de agosto de 2011, Lima - Perú. 
Consejo Andino de Ministros acordó, a través de la Declaración de Bogotá, poner en marcha el Plan Andino para el desarrollo de las Industrias Culturales con el objeto de "promover el fomento de las industrias culturales de la Subregión, mediante la implementación de un Sistema Andino para el fomento de las Industrias Culturales y Creativas, que permita un desarrollo equilibrado y armónico así como también el reconocimiento de la identidad, la diversidad cultural y los valores ciudadanos para la integración andina".

Asimismo, se comprometió a impulsar, entre otros temas relevantes, el Programa de Armonización de Estadísticas y Cuentas Satélite de la Cultura; el programa de formación artística y cultural; el desarrollo de un Sello Cultural Andino; la viabilidad de la creación de un Fondo para el Fomento de las Industrias Culturales y Creativas; y el Portal Cultural de la Comunidad Andina (CULTURANDE)

En este ámbito regional andino, también podemos aludir a otras expresiones de búsqueda de cooperación regional, por fuera de la propia institución de la CAN. Ejemplo de ello es la Organización del Convenio Andrés Bello de integración Educativa, Científica, Tecnológica y Cultural (Convenio Andrés Bello) ${ }^{21}$. Es un organismo internacional, intergubernamental, creado en virtud del Tratado suscrito en Bogotá, el 31 de enero de 1970, sustituido en 1990, goza de personería jurídica internacional, tiene por finalidad contribuir a ampliar y fortalecer el proceso dinámico de la integración de los Estados en los ámbitos educativo, cultural, científico y tecnológico, en beneficio de los estados miembros: Bolivia, Chile, Colombia, Cuba, Ecuador, España, México, Panamá, Paraguay, Perú, República Dominicana y República Bolivariana de Venezuela. Esta Institución procura favorecer el fortalecimiento de los procesos de integración y la configuración y desarrollo de un espacio cultural común. Busca generar consensos y cursos de acción en cultura, educación, ciencia y tecnología, con el propósito de que sus beneficios contribuyan a un desarrollo equitativo, sostenible y democrático de los países miembros.

En lo que respecta a la CELAC, se ha comenzado a trabajar en agendas comunes para el fortalecimiento de los espacios culturales como ámbito de integración regional. Fruto de ello fue el primer encuentro cultural celebrado en Surinam en marzo de 2013, en simultáneo con el XIX Foro de Ministros de Cultura y Encargados de Políticas Culturales de América Latina y el Caribe, una instancia coordinada desde 1989 por las Naciones Unidas para la Educación, la Ciencia y la Cultura (UNESCO). Esta primera reunión de autoridades del área cultural de la CELAC se concretó en el marco de una decisión política conjunta luego de la Cumbre de Jefes de Estados realizada en enero de 2013 en Santiago de Chile, donde presidentes

21 Ver: http://www.convenioandresbello.org/index.html 
de América Latina y el Caribe resaltaron la importancia de proyectar y discutir una agenda en común basada en el principio de integración. Con el acento puesto en el diseño de políticas orientadas a este fin, el evento se realizó bajo el lema "Cultura y Desarrollo Sostenible", entendiendo a la cultura como parte vertebral de los modelos de desarrollos políticos y económicos de América Latina y el Caribe. En esa oportunidad, el Foro se focalizó en tres temas primordiales de la coyuntura regional: Protección y promoción del patrimonio y las expresiones culturales; Fortalecimiento institucional y desarrollo de capacidades hacia la integración regional y las industrias culturales y creativas y Promoción del diálogo intercultural, la cohesión social y una cultura de paz y no violencia.

Entre los objetivos puestos por los responsables de la gestión cultural de la región, se puede apreciar, el entender la cultura como una herramienta poderosa de inclusión; de achicamientos de las asimetrías y de expansión hacia lo social y de construcción de igualdad. Esta valorización de la cultura puede ser percibida como un valor tangible en términos patrimoniales y edilicios, en lo que refiere a industrias culturales que generan trabajo, empleo y producción. Y lo intangible, que también es palpable, está indisolublemente ligado a la autoestima, a una sociedad que se conoce y por conocerse se interrelaciona y crea espacios comunes de dialogo y construcción de ciudadanía. Fruto de estos primeros pasos en la gestión cultural sudamericana se dio a conocer la Declaración de Suriname ${ }^{22}$, en la cual los delegados de los Estados Partes de la CELAC ratificaron:

“(...) el respeto por la diversidad cultural que caracteriza las identidades latinoamericanas y caribeñas, en tanto que sociedades multiétnicas, multiculturales y plurilingües, constituyen la base de la cooperación y de las acciones encaminadas al logro de la integración regional la que, conforme al espíritu y los principios de la CELAC, deberá construirse sobre la base del respeto al pluralismo y al derecho soberano de cada uno de nuestros pueblos, así como el respeto irrestricto de las normas y los principios del Derecho Internacional"23.

También se reconoció el mérito de las políticas culturales como promotoras de valores que reflejen el respeto a la vida, a la dignidad humana, a la pluriculturalidad, a los principios de justicia y tolerancia, y el rechazo de la violencia como elementos integrantes en la construcción de una cultura de paz que identifique a la región.

22 XIX Foro de Ministros de Cultura y Encargados de Políticas Culturales de América Latina y el Caribe y Primera Reunión de Ministros de Cultura de la Comunidad de Estados Latinoamericanos y Caribeños (CELAC). 14 y 15 de marzo de 2013, Paramaribo, Suriname. 23 Ibídem. Apartado 5. 
Si bien se han enunciado aquí las principales iniciativas culturales de los tres regímenes de integración regional de carácter macro, no se debe omitir que ad intra de cada uno de esos regímenes, coexisten sub procesos de integración y cooperación subregional que también le dan vida a la integración sudamericana y en donde los intercambios e intereses culturales son más palpables. Como ejemplo se puede mencionar la denominada ZICOSUR (Zona de Integración del Centro Oeste Sudamericano $)^{24}$. Este espacio regional, compuesto por provincias y regiones del norte de Argentina, Bolivia y Chile, Brasil y Paraguay; tiene como objetivo principal lograr la inserción de la subregión en el contexto internacional desde el punto de vista competitivo, desarrollando el comercio exterior con los mercados internacionales mediante la articulación de ejes de comunicación, así como también promover la integración social y cultural, como mecanismo para lograr el desarrollo económico-social de las regiones que la integran.

En el ámbito de la promoción cultural, se han plateado objetivos, tendientes a promover la identidad y participación efectiva de las regiones de la ZICOSUR en materia de cultura, difundiendo las especificidades de las distintas expresiones culturales de las regiones de la ZICOSUR., rescatando elementos comunes a nuestra identidad como América Latina y generando un programa de intercambio cultural permanente entre las regiones de la ZICOSUR, en donde actores como las Universidades regionales, juegan un rol trascendental en ese contexto.

Al igual que en el contexto del MERCOSUR CULTURAL, en la última reunión de la Comisión de Cultura del ZICOSUR, se ha comenzado a delinear políticas en conjunto que posibiliten un mecanismo de movilidad y seguridad para los instrumentos artísticos como así también, idear y gestionar procesos que permitan un intercambio de la producción cultural entre los miembros de la Institución, según el foro realizado en Bolivia en septiembre de 2010.

\section{CONCLUSIONES}

Acorde lo expresado, se torna un reto de la integración regional, la convergencia entre lo económico y lo cultural sin lo cual la ésta naufragará en una nueva retórica de los Estados sudamericanos e integrantes de los regímenes de integración aludidos.

El componente cultural para la construcción del espacio ampliado no debe soslayarse y hace a la diferencia entre una mera zona de libre comercio y otras etapas de integración con libre circulación de personas, bienes y servicios. Para entender esto se debe también enfatizar las cuestiones antropológicas y sociológicas en conjunto con las económicas y políticas.

24 Ver: http://www.zicosur.org.ar/Nueva_ZICOSUR/espanol/index1.php 
Para América del Sur la respuesta no es fragmentarse en comunidades originarias indígenas y comunidades eurodescendientes sino pensar en una unidad en la diversidad en el plano nacional y regional en tanto la integración debe plantearse desde la convergencia cultural para permitir la inserción desde un bloque regional con identidad propia.

Una mayor concienciación en los aportes y prácticas comunes entre los Estados Partes de estos regímenes de integración, posibilitarán un mejor y mayor acercamiento de los ciudadanos a las decisiones políticas de integración mancomunada. Pero también implica que los Estados se comprometan a fortalecer dentro de sus sistemas educativos y formación cultural, la existencia de particularidades culturales de los pueblos quela conforman y que sean conocidas por los demás ciudadanos de los Estados Partes de los mecanismos de integración. En tal sentido, queda como reto a consolidarse que en ámbitos como MERCOSUR, se propicien políticas públicas para la mayor difusión de la cultura, historia y lengua de los Estados Partes. Planes educativos y formación profesional sobre la lengua portuguesa o española en el caso de Brasil, se tornan prioritarios de profundizar y afianzar, ya que a través de ésta se construyen mejores instancias de comprensión e incorporación de la cultura de los pueblos que conforman los regímenes de integración regional sudamericanos.

\section{REFERENCIAS BIBLIOGRÁFICAS}

ÁLVAREZ Gabriel Omar (1999) "Integración regional e industrias culturales en el Mercosur: Situación actual y perspectivas". En GARCÍA CANCLINI Néstor y MONETA Carlos (eds.) Las industrias culturales en la integración latinoamericana. Buenos Aires: Eudeba.

CALDERÓN Fernando y SZMUKLER Alicia (1999) "Aspectos culturales de las migraciones en el MERCOSUR". Proyecto MOST Mercosur: espacios de interacción, espacios de integración-. UNESCO. Documentos de Debate, $n^{\circ} 31$. [online] Disponible en: <http://unesdoc. unesco.org/images/0011/001149/114955so.pdf $>$. Fecha de consulta [10/01/2013]

CEFIR (1998) “Dimensión Cultural de la Integración Regional de la Comunidad Andina”. DT.27/1998. [online] Disponible en: <http://cefir. org.uy/wp-content/uploads/downloads/2012/05/DT_27.pdf>, Fecha de consulta [15/01/2013]

FERNÁNDEZ SUÁREZ Edgar Gustavo (2007) Las Relaciones Culturales en el proceso de integración regional del MERCOSUR. Córdoba: Academia Nacional de Derecho y Ciencias Sociales de Córdoba.

JELIN Elizabeth (2001) "Los movimientos sociales y los actores culturales en el escenario regional. El caso del Mercosur". En SIERRA de Gerónimo (ed.) Los rostros del Mercosur. El difícil camino de lo comercial 
a lo societal. Buenos Aires: CLACSO.

KEOHANE Robert (1993). Instituciones Internacionales y Poder Estatal.

Ensayo sobre Teoría de las Relaciones Internacionales. Buenos Aires: GEL.

LÉVI-STRAUSS Claude (1999) Raza y Cultura. Barcelona: Edit. Altaya. MELLADO Noemí B (2013) "Regionalismo Sudamericano: Sus características". Revista de la Secretaría del Tribunal Permanente de Revisión. 1(1), pp. 137-159.

METHOL FERRE Alberto (1997) "Una Bipolaridad cultural. MERCOSUR - NAFTA". En RECONDO Gregorio (comp.) MERCOSUR. La dimensión cultural de la integración. Buenos Aires: Ciccus.

MUDROVCIC María Eugenia (2001) "Políticas Culturales en los procesos de integración regional. El sector editorial en el MERCOSUR". Revista Iberoamericana, 47(197), [online] Disponible en: <http:// revista-iberoamericana.pitt.edu/ojs/index.php/Iberoamericana/issue/ view/216> Fecha de consulta [20/01/2013].

MURILLO ZAMORA Carlos (2004) "Aproximación a los Regímenes de Integración Regional”. Revista Electrónica de Estudios Internacionales. (8), [online]. Disponible en: <http://www.reei.org/index.php/revista/ num8/articulos/aproximacion-regimenes-integracion-regional $>$. Fecha de consulta [10/01/2013].

RECONDO Gregorio (1997) MERCOSUR. La dimensión cultural de la integración. Buenos Aires: Ciccus.

REY Micheline (1997) "The rol of local and regional authorities in the development of programmes for migrants and minorities from and intercultural perspective". En COUNCIL OF EUROPE. Migrants and Minorities in the community. Studies and Texts $n^{\circ} 53$.

SANZ MANRIQUE Fernando (1998) "La integración cultural en la integración Internacional”. En Centro de Formación para la Integración Regional (CEFIR). $N^{\circ}$ 1998-9. [online]. Disponible en: <http://cefir. org.uy/documentacion/publicaciones-cefirv $>$ Fecha de consulta [15/01/2013].

TOURAINE Alain (1995) ¿Qué es la Democracia? Montevideo: Fondo de Cultura Económica.

VASCONCELOS Raphael Carvalho de (2013) "Regionalismo". Revista de la Secretaría del Tribunal Permanente de Revisión. 1(1), pp. 213-228. WEBER Raymond (2003) "Los nuevos desafíos de la cooperación cultural europea”. Revista Pensar Iberoamérica. Revista de Cultura. (2). 